\title{
The Perceived Vocabulary Strategies and Motivation Used by Learners of Chinese as a Foreign Language
}

\author{
Michael Kwarteng $18 \mathbb{D} \square$ and Dorcas Oteng Acheampong $28(\mathrm{D}$ \\ ${ }^{1}$ M.A. in Foreign Language and Literature, Nanjing Tech University, Nanjing, China \\ 2 M.A. in Foreign Language and Applied Linguistics, Nanjing Tech University, Nanjing, China \\ $\triangle$ Corresponding Author: Michael Kwarteng, E-mail: michaelkwartengpaah@gmail.com
}

\author{
ARTICLE INFORMATION \\ Received: February 01, 2021 \\ Accepted: March 19, 2021 \\ Volume: 3 \\ Issue: 3 \\ DOI: 10.32996/jweep.2021.3.3.3
}

\section{KEYWORDS}

Vocabulary, strategy, motivation, CFL learners

\section{ABSTRACT}

In learning a language, vocabulary forms the cornerstone of the whole process since vocabulary influences speaking, reading, and writing ability. This study involved the observation of CFL learners who are students in Nanjing-China. It aimed to critically assess the perceived challenges of CFL learners across various universities in Nanjing learning Chinese vocabularies, their adopted strategies and motivation in learning Chinese vocabularies and explore ways to improve CFL learner's proficiency. The study used a survey questionnaire to collect the data from 120 male and female Bachelor, Master and PhD students with different ages of 20 to 43 who are enrolled in 20 universities in Nanjing China. Based on certain Descriptive analysis and calculations, the findings of the study indicate that the participants indeed experience difficulties in learning Chinese vocabularies. Moreover, the results also revealed the participants' already laydown initiatives and strategies that are mostly influenced by their motivation to learn Chinese vocabularies. In addition, the researcher investigated the motivational levels of respondents towards learning Chinese vocabularies and how their source of motivation influences their adopted strategies. The findings showed that CFL learners are extrinsically motivated than intrinsically. The study recommends that teachers and educational authorities in China and for that matter Nanjing, should create more favorable conditions to boost the motivation level of foreign students to adopt and use appropriate strategies in learning Chinese vocabularies and consequently become proficient in Chinese language as a whole. The study ends in several recommendations to Chinese teachers and educational authorities as well as to foreign Chinese language learners with regard to the pedagogy of Chinese vocabularies.

\section{Introduction}

\subsection{Background}

Nowadays, it is widely acknowledged that learning strategies and motivation have become one of the main factors that successfully help students learn a second or foreign language (Oxford, 2003). This educational issue has been mainly tackled by researchers such as Kumaravadivelu (2001), Oxford (2003), Shuyi Yang(2014), Herrera \& Murry (2011), Herrera \& Holmes (2011), Ms. Natcha Puagsang (2017) etc. whose findings continually remind educators of the power of designing, adapting, or applying effective teaching methods in order to promote the use or creation of learning strategies that pave the way for learners to take charge of their own development in language learning and consequently increase their autonomous learning. One of the most key challenges that learners will face during the process of second language learning is learning vocabulary. Vocabulary has been recognized as crucial to language use in which insufficient vocabulary knowledge of the learners leads to difficulties in second language learning and its usage. Thus, in the case of learning the vocabulary in second language, learners need to be educated with vocabulary learning strategies. In light of these researches, this paper aimed at defining learning strategies in Second Language Acquisition (SLA) and at analyzing L2 approaches-Grammatical, Communicative, and Cognitive-to identify

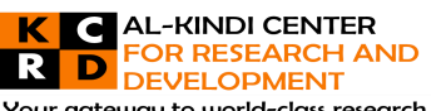

Your gateway to world-class research

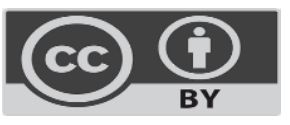

Published by Al-Kindi Center for Research and Development. Copyright (c) the author(s). This open access article is distributed under a Creative Commons Attribution (CC-BY) 4.0 license 
which of these approaches guide Learners in applying appropriate methods that promote the use of learning strategies in the process of SLA. It also discusses the effectiveness of the strategies in learning vocabularies in Chinese language by foreigners living in china which will be mostly used in culturally and linguistically diverse ways in China. Finally, the study further analyzes and recommend appropriate and pragmatic learning motivations which will fast track the teaching and learning of Chinese vocabularies by foreigners in China and consequently become better users of Chinese language in general.

\subsection{The need for the study}

This study explores the use of vocabulary learning strategies (VLS) specifically in the sphere of learning the lexical vocabulary nature of Chinese language and then investigates on appropriate motivation types that will accelerate the vocabulary learning process by foreign students in China. This study could operate as an extension of the exploratory studies that Richard Anthony LaBontee, Jr. (2013) and $\mathrm{Hu}$ (2005) conducted on strategies used by English speakers in learning Chinese tones. Tahsildar, Mohammad Nasim. (2019), Chinese Language Complexities among International Students in China. Also, a top up to Shuyi Yang (2014), Chinese as second language learners' beliefs about vocabulary acquisition. In addition, this research will add up to Ms. Natcha Puagsang's (2017) comprehensive study on vocational students' use of vocabulary learning strategies and their vocabulary knowledge. In an attempt to have an in-depth research about EFL learners perceived vocabulary learning strategies and motivation in order to add up to existing researches, questions on this study were put forward in the chapter of methodology, three instruments used for data collection in the form of questionnaire on vocabulary Learning Strategies, perceived impediments of learning vocabularies, their motivation and their already adopted strategies were dealt with in this chapter. The aim of the study was to detect the functions of CFL vocabulary Learning strategies, motivation, some challenges faced by CFL learners in China learning Chinese language vocabularies and how they can easily overcome them in the language learning process. The research further analyzed and recommend appropriate and pragmatic vocabulary learning strategies and motivations which will help CFL learners in China and the pedagogy of Chinese as a Foreign Language in general.

Also, the findings of this material are very useful to CFL Learners in Nanjing and China as a whole to adopt and use the appropriate recommendations and suitable vocabulary learning strategies to improve upon their vocabulary level and consequently become better speakers of the Chinese language in general. In addition, the outcome of the research is fruitful to teachers and educational authorities as to how they may direct and extrinsically motivate CFL Learners in China to learn vocabularies in the Chinese language with ease. The research targeted to draw attention on suitable motivations to accelerate Chinese vocabulary learning strategies by foreigners living in Nanjing and China as a whole.

\subsection{The Research objectives}

The intended objective of the study "Perceived Vocabulary strategies and Motivation used by Learners of Chinese as a Foreign Language." is to critically examine:

1. The CFL Learners perception on Chinese language vocabulary learning in China.

2. The perceived vocabulary learning difficulties encountered by CFL Learners in China.

3. The already-adopted Strategies by CFL Learners in learning Chinese language vocabulary in China.

4. The appropriate motivation and strategies suitable for CFL Learners in China in learning Chinese language vocabulary.

\subsection{Scope of the research}

The study is meant to overt, recommend and suggest appropriate and suitable Chinese language vocabulary learning strategies and motivation to CFL learners; other skills are not dealt with in this study. Finally, the results of this study is limited to CFL university learners in China and not for global consumption

\section{Literature Review}

\subsection{Theoretical framework}

\subsubsection{Krashen's Theory}

According to Krashen (1982), learned and gained competence, evolve in somewhat different ways. Language learning, in his opinion, takes place through the systematic analysis of rules, patterns, and norms, a study that helps one to discuss and actively apply the knowledge learned. On the other hand, language learning takes place in a somewhat different way, according to Krashen, since it evolves solely via "comprehensible input." That is, second-language students learn how to communicate in a way that is both clear and essential to them. They gain from subconsciously by focusing on meaning. A language that goes only a step beyond the constructs that second-language students have already learned (or, in Krashen's terminology, I +1 , where I reflect language at the students' current level of competence) is the most important feedback for acquisition. The acquisition will not occur regardless of how suitable the feedback is if a student's "affective filter," or a set of emotional responses that hinder understanding of meaning, is developed. Pertinently, Krashen maintains that learning only happens in a convoluted way when it comes to acquisition. Only if second-language students successfully track their language output and provide their own 
grammatically correct comprehensible feedback would this be possible. This self-produced input is then added to the total required for acquisition to occur (Krashen, 1982; Krashen and Terrell, 1983).

\subsubsection{Behaviorism Theory}

The behaviorist model used in L1 and L2 learning has no major differences. In L2 learning, the same concepts apply, such as practice, imitation, reinforcement/feedback, and habit forming based on a stimulus-response model. This theory assumes that all learning is the same, with no distinction made between L1 and L2. The teaching method/approach known as Audiolingualism (coined by Professor Nelson Brooks in 1964) represents the application of behaviorist theories by stressing the structured presentation of grammatical types from the simplest to the most complicated. Repetitive exercises, no translation, no clarification of grammatical laws, word sense learned in context, and more spoken practices are the key features of this practice. As a result, a lot of dialogue memorization, repetition, and exercises are used (Suharno, 2010).

\subsubsection{Interactionism Theory}

The sociolinguistics and language used for communication views are closely linked to the interactionist model. The relationship between second language learners and native speakers is emphasized in second language learning for adolescents (aged 20 and up). The comprehensible input (meaning), which was then related to innatist models, was the subject of early studies of this relationship. On the other hand, other scholars suggest that the learning process encompasses not only comprehension (comprehensible input), but also communication (language use). As a result, the optimal learning condition combines both variables. The linguistic context - the way(s) in which language is used with and around the learner - is often linked to such a situation. Input, negotiation, performance, and interactional feedback all play a role in second language learning, according to the report. The interactionist model's consequences can be seen in the practice of Communicative Language Teaching Approaches (CLTAs), which cover a broad range of topics and activities, including functional-notional, content-based, thematic, task-based, and so on (Goh, 2004, p.41-42).

\subsection{CFL Learners in China}

Since most research is performed by Chinese scholars and published in Chinese journals (Ma et al., 2017), English-language research on critical issues in CFL in China is limited. The authors describe a rise in research interest in pedagogical creativity to include personalized instructional methods to help CFL learners navigate the challenging target language in their systematic analysis (Ma et al., 2017). This review includes recent research on key pedagogical topics such as language proficiency, improvement of one of the four language skills, language-character integration" versus "separation, and creation of teaching materials. Constructivism and communicative techniques, both rooted in Western language pedagogy, seem to be receiving more publicity (Mao, 2010; Shao, 2013; Zhao, 2008). Zhao (2008), for example, explores the definition and feasibility of developing task-based oral Chinese teaching systems to resolve issues such as student frustration with oral communication classes and low Chinese language proficiency. Nonetheless, the majority of studies published in Chinese journals are nonempirical (Ma et al., 2017), and only a few look at student perspectives, especially concerning language difficulty and motivation concerning creative pedagogy. Xu and Yao (2014) investigated how teaching and learning methods, as well as students' individual experiences and desires, influence learner motivation. The findings indicate that the language-character separation approach outperforms the language-character integration approach in terms of enhancing students' integrative motivation and learning experience. Furthermore, exposure to Chinese culture may increase learner motivation (Ding, 2014). Students have a deep need to understand the learning objectives and the learning process, enjoy learning Chinese with classmates of similar Chinese proficiency and different nationalities, and tend to work in groups of three to five, according to Ni (2007), who conducted an empirical study of 900 students and 150 teachers in China.

\subsection{The learning difficulties}

In their study of international students, Yu and Watkins (2008) discovered that second-year international students face more difficulties learning Chinese than students in other years. Furthermore, in his study on the difficulties of teaching Chinese to foreign students, Halliday (2014) makes three recommendations. To begin with, he emphasises that the best Chinese teachers are those who speak the same language as their students. Second, he claims that Chinese characters should not be taught at a young age, and third, he emphasises the importance of phonological accuracy in Chinese. Furthermore, (Wang, Perfetti, \& Liu, 2005) discovered in a study conducted at an American college that students who study Chinese for one semester face significant challenges in learning the tones, which are primarily due to a lack of tonal characteristics in the students' native languages. They go on to say that another challenge for Chinese foreign language learners is a large number of homophones in the Chinese language.

Furthermore, (Gao, 2007) looks at the challenges that American students face while studying in China. He distinguishes between three types of barriers: perceptual, motivational, and structural. The participants' cognitive difficulties, according to Goa, are triggered by their poor language proficiency. 
On the other hand, research indicates that the process of learning a second language is affected by the first language due to several factors. Factors such as systemic similarities and disparities, prior experience, and first language proficiency, among others, have both positive and negative effects (Drakhsahn, 2015). According to Hayati (2008), the degree of variation between the first and target languages represents ambiguity, while the degree of similarity represents simplicity. According to Bhela (1999), learners appear to rely on their native language structures when writing and speaking in a target language. Language intrusion, according to Bhela, is a mistake that can be traced back to the first language. Karim and Nassaji (2013) investigate native language interference in second language writing capacity and discover that native language interference has a major effect on second language writing performance. In their research on the interference of native and second languages, Fatemi, Sobhan, and Abolhassan (2012) found that the disparity in consonant clusters in native and second languages creates difficulties with second language pronunciation. However, according to Jin (2006), only a few studies have looked into the effect of specific linguistic techniques on learning Chinese.

Several recent studies have also shown that international students face linguistic complexities in their language success and proficiency while studying a second language (Hayes and Lin 1994; Kagan and Cohen 1990, and Ying and Liese 1994). Chinese is one of the most difficult languages to learn, particularly for non-native speakers. Learning various Chinese linguistic elements such as strokes, which takes a long time (Lee and Kalyuga, 2011), is one of the most difficult aspects of learning Chinese. This difficulty stems from the lack of correspondence between the characters and their pronunciations. Furthermore, the large number of Chinese characters, which takes a long time to understand, adds to the difficulty of learning Chinese as a foreign language for Chinese students (Sung and Wu, 2011). Xing (2004), on the other hand, claims that many upper-intermediate students struggle to use upper-intermediate vocabulary in everyday communication and instead use lower-intermediate words and phrases like novices.

Tahsildar (2019) conducted research on features related to Chinese linguistic complexities among international students enrolled in Chinese courses in China. The study used a survey questionnaire to collect the data from 147 male and female Bachelor, Master and PhD students enrolled in basic Chinese classes in two universities in China. Based on certain Descriptive and ANOVA calculations, findings of the study indicate that the participants indeed experienced Sound Similarities, Chinese Characters and Chinese Tones as the main features related to Chines linguistic complexities.

\subsection{Vocabulary learning strategies \\ 2.4.1 Vocabulary}

It is the collection of words that an individual possesses in a language (Linse, 2005:121). Hatch and Brown (1995:1) defined vocabulary as a list of words for a particular language or a list of set of words that individual speakers of language might use. In other words, vocabulary maybe define as the quantum of words a language user possesses in that particular language. The success of a language user depends on the level of vocabularies under possession which will determine the level of fluency, writing ability and proficiency level. Most often than not, the acquisition of L1 vocabularies, is natural. Language users get as many as possible of vocabularies once they stay in touch with the environment without any difficulty which makes them confident and proficient in using the language. However, in L2 learning the process differ.

\subsection{Strategy}

According to Jasmina Hasanbegovic "learning strategies refer to learners self-generated thoughts, feelings, and actions, which are systematically oriented towards the attainment of learners goals", (2006). Weinstein and Mayer (1986) defined learning strategies (LS) broadly as "behaviors and thoughts that a learner engages in during learning" which are "intended to influence the learner's encoding process" (p. 315). Later Mayer (1988) more specifically defined LS as "behaviors of a learner that are intended to influence how the learner processes information". In other words, strategy may be defined as a deliberately laydown plans for achieving a desired objective. The realization of every objective depends on a well-structured strategy.

Therefore, vocabulary learning strategies may be defined as the process and actions that language learners consciously and deliberately deploy to help them learn and use words in a particular language more effectively. It can also be seen as thoughts and actions, consciously chosen and operationalized by language learners, to assist them in carrying out a multiplicity of tasks from the very outset of learning vocabularies to the most advanced levels of a target language.

\subsubsection{Determination strategies}

To determine the meaning of an unknown word, one strategy is to analyse the unknown word, its constituent elements, or the surrounding context. The learner might be able to recognise the word as an entity, state, action, or quality after identifying the part of speech. It's also possible to look at inflectional or derivational word parts. Because English has a limited number of inflections, learners should encounter and understand them quickly. Although derivational affixes are far more numerous, they provide invaluable information about word class and definition. Nation (2001) cites a study that found that if the base word was recognised, 60 percent of words containing the prefixes un-, re-, in-, and dis- could be understood. 
If the learners' L1 and L2 are similar, cognates can exist that make guessing easier. Despite being unrelated to English, Japanese has a steadily growing number of 20 kana loanwords, mostly derived from English. According to Daulton (1998), Japanese loanwords compare with 38 percent of the 2,000 most common words and approximately $26 \%$ of the University Word List. While there is a risk of using loanwords as cognates since not all of them are used in the same way as in English, there is still a large number that could help Japanese English learners. Many foreign language learners use dictionaries, even though they lack the scope of processing that comes with guessing strategies. Although monolingual dictionaries can provide better quality information and improve learners' ability to paraphrase, Schmitt's (1997, p.209-210) survey of attitudes toward learning strategies revealed that bilingual dictionaries were favoured. This might be due to the sense of security they provide - Grabe and Stoller (1997, p.112) noted a learner's unwillingness to give up his "accuracy anchor".

Dictionary skills must be learned in the same way as other skills to reap the greatest value. Learners must be taught when not to use dictionaries or be overused, causing them to overlook other techniques and lengthen the time it takes to complete tasks. Nation (2001, p.283-284) provides a review of studies on dictionary usage, which show that using a dictionary enhances vocabulary comprehension for all but high-level learners, but also increases completion time. According to Nation (2001:239), inference skills should be prioritized, but that using dictionaries afterward has a substantial impact on retention.

\subsubsection{Social strategies}

To decide word meanings, some social techniques can be used. Teachers are a valuable source of knowledge for students, and they can provide L2 vocabulary information in a variety of ways. A direct translation is possible if the instructor knows the learners' first language. While this is the quickest and most attractive approach for students, there are several cautionary notes to be made. Learners can assume that a translation of an L2 word has all of the functional and stylistic properties of its closest L1 counterpart, and thus use it in the same way they would in their L1.

There's also the possibility that learners who are used to hearing L1 translations will become dependent on them, which will hinder their ability to have L2 conversations. Teachers may also include L2 paraphrases, synonyms, or examples of sentences that use the unfamiliar term. These approaches would be more useful than translation if the learners intend to use the L2 productively. However, the instructor must understand the information required to use each term while still maximizing class time.

While classmates may provide this information instead of teachers, some students will believe that information from a teacher is more accurate. If classmates cooperate in providing details, the entire class will benefit from improved paraphrasing skills and a reduction in reliance on the instructor. Knowledge may also be consolidated using social techniques. Sanaoui's (1995) research emphasized the importance of students creating their opportunities for language use outside of the classroom. Outside of class, students can make an effort to use the L2 together, or seek opportunities to communicate with native speakers or even their instructor. There are many advantages to practicing L2 vocabulary in a less formal environment. To begin with, the more opportunities a learner has to communicate, the more opportunities he or she will have to experiment with new words. Learner enthusiasm and successful processing are likely to improve as a result of the experience of using the language for genuine communication (Schmitt 1997, p.211).

\subsubsection{Memory strategies}

Researchers have discovered a slew of strategies that students use to help them remember vocabulary. For example, Schmitt's (1997) taxonomy lists 27 different memory strategies. When learning a new word, one approach uses pictures to help form a deeper connection with the word and its context. These images may be taken from personal experience, sketched in notebooks, or created in mind. This is an outstanding example of how a deeper degree of processing can be accomplished without being too taxing and thus demotivating - another broad group of techniques aid retrieval by connecting or grouping words. Individual words enter into some semantic relationships, including synonymy, antonymy, hyponymy, and meronymy, according to facts (Miller and Fellbaum, 1991, p.199-204). Since the added meaning can make retrieval easier, using words in sentences can also be considered a memory technique. It has also been shown that spatially grouping L1 words increases recollection (Bellezza, 1983, in Schmitt, 1997, p.213). When L1 words are grouped into patterns, they are easier to remember than when they are in a sequence. Schmitt claims that the same strategy would work with L2 vocabulary as well (Schmitt, 1997, p.213).

A final set of memory strategies relies on elements of word knowledge to help people remember what they've learned. This involves focusing on the word's orthographic or phonological form, memorizing affixes and origins, and studying the word class. As taught in the Total Physical Response Method (Richards and Rogers, 2001:73-74), matching such words to their corresponding physical actions can also help with recall (Schmitt, 1997:215).

\subsubsection{Cognitive strategies}

The mechanical dimensions of learning vocabulary are the subject of cognitive strategies. These strategies may be needed in the course, assigned as homework by the instructor, or simply the behaviors of individual students. Vocabulary notebooks are a 
perfect way to help students become more self-sufficient. The notebooks help learners gain greater self-awareness while also eliminating the instructor from some of the learning processes by allowing them to pick the words that they will use. Schmitt and Schmitt (1995:139) stress the importance of encouraging students to use their vocabulary to enhance their sense of exploration. Fowle's introduction of vocabulary notebooks to a Thai school resulted in improved metacognitive awareness in the form of appropriate technique collection, a deeper understanding of vocabulary learning demands, and a higher tolerance for uncertainty $(2002$, p.385).

In Schmitt's (1997) study of learning methods, learners often used repetition as a cognitive technique. Learners repeat the words verbally or in writing to develop their vocabulary. This approach lacks the scope of processing that researchers suggest, and it appears to examine only a small portion of the information required for communicative use.

According to Nation (2001, p.383) and Read (2004, p.148), learners in the past have used rote techniques to achieve high levels of mastery. Taking notes and highlighting terms, using the vocabulary pages of textbooks, and marking physical items are all examples of cognitive strategies. Both of these strategies can be said to help with noticing, which is a crucial first step in getting something into conscious focus (Schmidt, 1990). When learners perceive something, they are more likely to pay attention to it, and the process of acquiring the object begins.

\subsubsection{Metacognitive Strategies}

It is important for students to become conscious of their learning and how they can progress most effectively. Many of the behaviors identified by Sanaoui (1995) as being used by active learners may be classified as metacognitive strategies, as they represent the ability of learners to find opportunities to learn and then document and review those experiences. Having enough opportunities to learn is the first prerequisite for a learner. It is important for students to become conscious of their learning and how they can progress most effectively. Many of the behaviors identified by Sanaoui (1995) as being used by active learners may be classified as metacognitive strategies, as they represent the ability of learners to find opportunities to learn and then document and review those experiences. Having enough opportunities to learn is the first prerequisite for a learner. As a number of the studies mentioned earlier in this chapter have demonstrated, learning is likely to be haphazard and erratic without such a structure in place. Finally, students should think about which terms merit the most consideration. Since most students only have a limited amount of time to research, learning to skip over occasional or technical vocabulary that isn't essential to overall comprehension will help them be more effective (Bennett, 2006).

\subsection{Language learning Motivation \\ 2.6.1 Motivation}

Motivation is basically one of the most influential factors in all human endeavors, including learning vocabularies in a language mostly second language. The commonest question people ask themselves when doing something is "why". This is because any reasonable being wants to be aware of the rationale behind anything they do especially when it comes to leaning.

Motivation refers to "the reasons underlying behavior" (Guay et al., 2010, p. 712). Broussard and Garrison (2004) broadly define motivation as "the attribute that moves us to do or not to do something" (p. 106).In other words, motivation is a word derived from the word 'motive' which means reason, needs, desires, wants or drives within the individuals. It is the process of stimulating people to actions to accomplish certain goals.

According to Stipek (1996), early approaches to the study of motivation were rooted in the literature on extrinsic reinforcement. Within this literature, all behavior, including achievement, was believed to be governed by reinforcement contingencies. Proponents of this approach included B.F. Skinner, who identified different types of reinforces. Positive reinforcers, or rewards, are consequences that increase the probability of a given behavior they were made contingent on, whereas negative reinforcers are consequences that increase the probability of a given behavior by removing or reducing some negative external stimulus. According to Macintyre et al., (2001), motivation is defined as an attribute of the individual describing the psychological qualities underlying behavior with respect to a particular task. This goal-directed behavior shows itself through distinct actions of the motivated individual. Dornyei (2001b) described explicitly that, the motivated individual expends effort, is persistent and attentive to the task at hand, has goals, desires and aspirations, enjoys the activity, experiences reinforcement from success and disappointment from failure, makes attributions concerning success and or failure, is aroused, and makes use of strategies to aid in achieving goals. Motivation should be viewed as a hybrid concept, an internal attribute that is the result of an external force (Dornyei, 2003). Dornyei (2001c) states that motivation energizes human being and provides direction. Crookes \& Schmidt (1991) identify motivation as the learner's orientation with regard to the goal of learning a second language.

Vocabulary learning and for that matter language learning is not a day journey therefore there must be a motivation either integrative or instrumental to keep learners going with anxiety and enthusiasm about future expectations. Motivation is generally divided into two by scholars. Intrinsic motivation is motivation that is animated by personal enjoyment, interest, or pleasure. As Deci et al. (1999) observe, "Intrinsic motivation energizes and sustains activities through the spontaneous 
satisfactions inherent in effective volitional action. It is manifested in behaviors such as play, exploration, and challenge seeking that people often do for external rewards" (p. 658). Extrinsic motivation is centered on external influences that stimulate action.

According to Krashen (1988, p.22), there are some factors linked to motivation, and these factors often attempt to contribute to the ability of the second language learner; integrative and instrumental factors are linked to motivation. Integrative motivation is driven by a desire to be accepted as part of a culture or a society that speaks a second language. It is centered on the desire to learn the second language because of the need to learn about, interact, or socialize with the people who use it or because of the intention to engage or integrate into the second language in that culture using the same language; but it also requires a great deal of emotion or affective factors (Saville-Troike, 2006, p. 86). Instrumental motivation expresses the values of strictly practical value in second language learning to increase the academic achievement, job prospects, or business opportunities of learners, give them more recognition and power, access scientific and technical information, or just pass an exam or a course of study in school (Saville-Troike, 2006, p. 86).

\subsubsection{Intrinsic Motivation}

It is the act of performing an activity without any clear external rewards. You do it under the influence of personal enjoyment and interest, rather than as a result of an outside incentive or pressure to do it, such as a reward or punishment.

In other words, always the reward for intrinsic motivation by performing a task is by accomplishing the same task itself rather than anything else. For example, when someone decides to play football, the source of motivation is to enjoy playing soccer unless the game is being played at the professional level. People don't do such activities for some external reward. Intrinsic motivation is always influenced by three forces namely; Autonomy, Mastery and Purpose.

Autonomy: when people want to expand their territory and have self-ownership of their own work and skill development they are encouraged and motivated intrinsically to go all out by performing an act without any form of external influence. For example, when an individual language learner, develops the mentality of expanding his ability of using that particular language in a community without any external reward, the determination becomes so high to go all out since they are not forced for the endeavor.

Mastery: This is another important element to intrinsic motivation which is described as the desire and the willingness to get better at something that matters. People with such a kind of motivational mentality see no limits to their potential development and are given the necessary tools to continue improving their skills. Sometimes, because individuals wants to get better, the beginning stage becomes very tough.

Purpose: This refers to the desire to do things in service of something larger than ourselves. For example, most second language learners are often intrinsically motivated to learn for the basic reason to survive within certain vicinity than anything else.

\section{Characteristics of Intrinsic motivation}

a. There is freedom towards action.

b. There is emotional connection attached to action.

c. There is process enjoyment in the action.

d. Attitude towards action is unlimited.

\subsubsection{Extrinsic motivation.}

Most often, we do things not necessarily we enjoy them, but because they are demanded from us or we want to obtain something else. When this happens, we are extrinsically motivated to do so. The type of motivation that opposes intrinsic motivation is extrinsic motivation. Under this, individual actions are influenced by external reward like money, fame, grades, praise and others. Actions are not done or performed from the willingness of individual but rather under the control of certain stimuli. For example, a student may learn a second language not because he wants to speak the language from his own willingness but to pass an exam or maintain a scholarship. In this situation, when the scholarship is taken or after exams, the individual may stop learning the language since it's not the personal willingness. There are four types of extrinsic motivation namely; external regulation, introjected regulation, regulation through identification and integrated regulation.

\section{Introjected Regulation}

This is the type of extrinsic motivation where by the individual does something but not fully accepting it within. For example, a Chinese language student who spends much time practicing Chinese characters for an examination because he believes if he does not perform well, he won't have good grades, and authorities will look down on him or lose a scholarship. This type of regulation is still perceived as controlled because introjected behavior is exhibited due to internal pressure to reduce guilt or anxiety, enhance ego or pride, or to maintain self-esteem or feeling of self-worth. Although the person has accepted the goal of 
the activity as necessary, and the intention is within yet it is not experienced as a "free choice." Introjected motivation is still not a desired type of motivation because the action is controlled or coerced by internal irregularities rather than being self-directed.

\section{External Regulation}

This is the situation of performing an activity to satisfy an external demand or receive an externally imposed reward within certain period. For example, a student can study hard just to get a good grade to receive a reward from his parents or just to study abroad. Although the behavior is intentional and there is hard work attached to yet, it is controlled by an external source. As students, we are supposed to learn to become knowledgeable to survive within society in the future. However, if our actions are externally regulated then it is considered as lack of willingness. A person experiences an externally regulated behavior as controlled rather than autonomous. External regulation is the least desirable type of motivation and is typically used to contrast with intrinsic motivation.

\section{Regulation through Identification}

This is a less controlling form of extrinsic motivation. Identification means the person deliberately values a goal and believes the activity is personally relevant. Here, the individuals don't do things just because they feel they should. An example would be a student who studies very hard for the SAT exam because getting into college is important to him. Getting into college is a selfselected goal. Even though the behavior is extrinsically motivated, it is still relatively autonomous. It would be different if a student does it because they think they "should" go to college like everyone else and will feel like a failure unlike introjected regulation and external regulation.

\section{Integrated Regulation}

It is the situation where the individual has fully taken in the reason for action, i.e., a person has examined the cause and found it compatible with their own values and needs. Then the action becomes self-initiated. It is autonomous and not controlled by any form of external cause. Despite being extrinsic, integrated motivation shares many similar qualities as intrinsic motivation and is the best extrinsic motivation type. Some researchers even refer to integrated regulation as intrinsic because the person has completely internalized the extrinsic cause into their values. When intrinsic motivation is not possible, integrated regulation is the next best option.

\section{Characteristics of Extrinsic Motivation}
a. Action is performed mostly as a result of pressure.
b. Lackadaisical attitude towards action.
c. Action is performed due to the fear of punishment.
d. There is always reward before action.

\subsection{Previous Studies}

Although the interest in motivation among $\mathrm{L} 2$ researchers is very high, very few studies have examined motivation's strong vocabulary learning effects. Among these, Zheng (2012) confirmed the genetic role of motivation in L2 vocabulary learning among a sample of Chinese EFL college students; and Fontecha and Gallego (2012) reported a positive relationship between motivation and L2 Spanish vocabulary knowledge. However, none of the authors differentiated between intrinsic and extrinsic motivation; consequently, how these two types of motivation might be differentially related to L2 vocabulary knowledge remains uncertain. A series of studies by Noels and her colleagues in Canadian contexts, for example, found that intrinsic motivation was an important indicator of students' motivational intensity, persistence, and final grades, with a small to medium effect size (Noels, Clement, \& Pelletier, 2001; Noels, Pelletier, \& Vallerand, 2000).

In addition, there have been a great deal of research on how to motivate people to learn languages. Mandell (2002) found that the majority of beginning Spanish learners were enrolled in language classes to meet the institution's requirement, based on his study of university-level Spanish learners.

Husseinali (2006) examined the motivation of Arabic language learners at a major university in the United States and discovered three major forms of orientations: instrumental, identity, and travel and culture. According to the findings of "Orientations to Learning German" (Noels, 2005), heritage language learners were more likely than non-heritage language learners to learn German because it was an important part of their self-concept.

Wen's (1997) analysis of the motivating factors of students from Asian and Asian-American backgrounds studying Chinese at American universities showed that interest in Chinese culture, as well as a desire to understand one's heritage and culture, motivated students to learn Chinese.

Gardner and his colleagues (Gardner \& Lambert, 1972; Gardner, 1985) suggested two motivational orientations that suggest students' key motivations for learning a language when looking at motivation for learning a second language. The first 
orientation is integrative, which means that "the student wants to learn more about the other cultural culture because he is interested in it in an open-minded manner to the point of being accepted as a member of that other group" (Gardner \& Lambert, 1972, p. 3). Integrative orientation entails emotional affiliation with the target cultural group, positive attitudes toward the language community, and interest and desire for social interactions with the language community, all of which represent a better outlook toward the L2 and its culture (Gardner, 2001; Csizér \& Dörnyei, 2005). The second orientation is instrumental, in which the student aims to gain unique advantages from learning the language, such as job opportunities. Practical considerations and utilitarian beliefs, as well as a learner's expectations of the language's advantages, such as having a better career, traveling, making friends, and understanding international media, are all examples of instrumentality (Gardner, 2001; Csizér \& Dörnyei, 2005). Both orientations are important predictors of language proficiency in Chinese HL learning (Lu \& Li, 2008; Yang, 2003).

Wen (1997) looked into the motivating factors of students studying Chinese at the university level in the United States who come from Asian and Asian-American backgrounds. The research included 77 students who were at the beginner and intermediate stages of proficiency. The knowledge was obtained using a survey tool. The study questions were answered using factor analysis, regression procedures, t-tests, and correlation coefficients. The study's findings show that students' initial motive for studying the Chinese language is an inherent curiosity in Chinese culture and a desire to recognize their cultural heritage.

In recent times, CAL researchers have broadened their scope to look at motivation fluctuations as a function of the learning experience, as well as the role of instructional settings like educational subject dimensions. Cai and Zhu (2012) used the LMSS as a framework to investigate the effect of an online learning project on CAL learning motivation among university students in the United States, finding that L2 learning perceptions dramatically changed pre and post online projects.

In a Danish university, Ruan et al. (2015) investigated the impact of task-based teaching on the motivation of beginner CAL students. Unfocused tasks, as well as tasks involving group work, learner autonomy, interactions, and cultural elements, were found to motivate learners. More research into the relationships between motivation, learning experience, and the learning context is required to build on these current studies of CAL learners' motivation (Wen, 2018; Cai and Zhu, 2012).

Having summarized the major studies on language and vocabulary learning strategies as well as motivation, I will now focus on establishing the context for vocabulary learning strategies on CFL learning. However, we must recognise that the line that separates research on language learning strategies from that of vocabulary learning strategies is by no means clearly defined. As Sharwood Smith (1984) points out, studies on vocabulary learning overlap with those on communication strategies (quoted in Gass 1988: 93).The main objective of research on vocabulary acquisition is the investigation of vocabulary development and the description of the main processes which underlie acquisition of a particular language component. According to Maiguashca (1993), different lines of research stem from this common objective: the attempt to differentiate passive from active, productive/receptive vocabulary; the influence of specific teaching methods and techniques on vocabulary learning; and the description and explanation of the learning processes revealed by learners' lexical errors and vocabulary learning strategies. The main goal of studies on vocabulary learning strategies is to discover how words are learnt and what part is played by different processes such as lexical inference, guessing the meaning of words from the context, memory processes, lexical simplification, and finally, lexical transfer from L1 to L2. As Schmitt (1997) notes.

Many articles and a considerable number of books have been published on both language learning strategies and vocabulary learning as well as motivation over the past twenty-five years. Nevertheless, little has been published on vocabulary learning strategies and motivation. The few studies we can find either tend to focus on a very small number of strategies or examine the use of strategies by a small number of learners; in addition, a comprehensive taxonomy of strategies is lacking in the area of vocabulary learning strategies and motivation; the result according to Schmitt is a lack of large-scale studies based on comprehensive taxonomies.

In an attempt to overcome these drawbacks, Zhang, et al (2016) from Michigan State University, East Lansing, Michigan, USA conducted a study which focused to examine L2 vocabulary learning, focusing on the joint influence of different motivational factors and learning strategies on the vocabulary breadth of adolescent learners of English as a foreign language (EFL) in China. Since the researcher believed that the mechanisms through which learners regulate their motivation and learning strategies remain unclear, Sample participants of 107 tenth graders (68 females, 39 males) in China were selected for the research. The data were collected through two questionnaires, one assessing students' motivation towards English-vocabulary learning and the other targeting same students English vocabulary learning strategies, along with a test measuring vocabulary breadth. The results through Structural equation modelling (SEM) indicated that learning strategy partially mediated the relationship between motivation (i.e., a composite score of intrinsic and extrinsic motivation) and vocabulary learning. Separate SEM analyses for intrinsic (IM) and extrinsic motivation (EM) revealed that there were significant and positive direct and indirect effects of IM on 
vocabulary knowledge; and while EM's direct effect over and above that of learning strategies did not achieve significance, its indirect effect was significant and positive. The findings finally, suggest that vocabulary-learning strategies mediate the relationship between motivation and vocabulary knowledge. In addition, IM may have a greater influence on vocabulary learning in foreign-language contexts. In spite of this useful outcome, the target objective is not CFL learners in China that the new study will focus and throw more light at.

Shuyi Yang (2014) also conducted a survey that examined L2 Chinese learners' beliefs about vocabulary acquisition. In doing this, 59 participants provided their views in a 5-point-scale Beliefs about Chinese Vocabulary Acquisition Inventory. Semi-structured interviews with 6 participants were also adopted by the researcher. Results proved that, most learners believed that it is essential to know the pronunciation of words and that repetitive practice would be very helpful. They also agreed that word pronunciation fails to provide useful information to assist in retaining and retrieving meaning, implying the indirect phoneme-meaning relationship in Chinese words. In terms of the characters in words, learners attached importance to character learning and preferred writing drills to structure analysis. Regarding word meaning and vocabulary size, most participants tended to adopt learning strategies of communicative nature. Pedagogical recommendations were that instructors should be aware of learners' different beliefs, design various communicative activities, and introduce effective learning strategies.

In addition to solve this same problem, Schmitt compiled a taxonomy from different sources such as reference books, textbooks, and L2 language teachers' interviews with learners. He obtained a list of 58 strategies which he arranged into a framework based broadly on Oxford's (1989), but also on Cook and Mayer (1983) and Nation (1990). Schmitt's taxonomy falls into two groups of strategies: discovery strategies and consolidation strategies. The former comprises determination strategies and social strategies: social strategies, memory strategies, cognitive strategies, and metacognitive strategies. Schmitt also conducted a survey in Japan with 600 Japanese students of English. This large sample of subjects fell into four groups: junior high school students, high school students, university students and adult learners. In Schmitt's own words, the purpose of this study was "to assess which vocabulary learning strategies learners actually use and how helpful they believe them to be" (1977: 199). He found that among the six most-used strategies were: using a bilingual dictionary, guessing from textual context and asking classmates for meaning as strategies to discover meaning, and verbal repetition, written repetition and studying the spelling as strategies to consolidate meaning. Regarding the most helpful strategies, he found that there was a close correspondence between the most-used strategies and the most helpful ones. According to Japanese students' perceptions, the most helpful vocabulary learning strategies were: using a bilingual dictionary, written repetition, verbal repetition, saying a new word aloud, studying a word's spelling and taking notes in class. The present study seeks to fill the gap in large-scale surveys of vocabulary learning strategies for L2 by presenting a study closely resembling the one conducted by Schmitt. The points in common lie mainly in the use of a similar self-report questionnaire, a similar number of subjects and similar groups. However, several changes will be introduced: for instance, I will not assess how helpful students believe strategies to be, I will introduce the contrast between English and Chinese as L2.

Also, Ms. Natcha Puagsang's (2017) comprehensive study on vocational students' use of vocabulary learning strategies and their vocabulary knowledge which focused mainly on the relationship between vocabulary learning strategies and vocabulary year levels among first high vocational certificate students from three fields of study namely engineering, accounting, and hotel and tourism in five government vocational colleges in Krabi Province in Thailand. The study's purpose was to identify the vocabulary learning strategies, explore the vocabulary levels, investigate the relationship between VLSs and vocabulary levels of 242 first year high vocational certificate students from the foregoing mentioned departments in the second semester 2014. A VLSs questionnaire, a vocabulary level test, and a semi-structured interview were used as the instruments for the study. The statistics employed to analyze the data of the study was mean scores, standard deviation, ANOVA, and Pearson's Correlation. The findings revealed that, the students employed all the five categories (determination strategy, social strategy, memory strategies, cognitive strategies and metacognitive strategies) at the frequency of sometimes. From the findings, social strategies were ranked as the most frequently used strategy. In addition, the use of 5 out of 39 VLAs was significantly different among the students from the three field of study. The results from the Vocabulary Level Test (VLT) proves that, the students average score of 1000 and 2000 word level were higher than those of 3000, 4000 and 5000-word level. With regard to the relationships between VLSs used by participants and their vocabulary knowledge, there were weak significant correlations between all the five strategies categories at the 1000 and 2000 word levels. In addition, the relationship between VLSs and vocabulary level of students in the three fields of study were explored. For the engineering students, it was reported that their 2000-word level knowledge was significant correlated with cognitive and metacognitive strategies at a very weak rate. The hotel and tourism students revealed that their 1000- word level knowledge was correlated with demonstration, memory, and metacognitive strategies at a weak level. Moreover, their 4000-word level knowledge was correlated with determination and metacognitive strategies at a weak level. Conversely, the correlation between these two variables was not found among the accounting students. In order to improve students vocabulary knowledge, the findings of the researcher recommends that, teachers might suggest to students to employ a wider range of VLSs. 
To conclude, it is clear from the forgoing literature that, second language learners do experience a lot of challenges as a result they also adopt to numerous strategies that will push them to accomplish their L2 learning task which is influenced by their source of motivation.

\section{Methodology}

\subsection{Research Questions}

1. What are the perceived vocabulary learning difficulties encountered by CFL Learners in China?

2. What are the strategies adopted by CFL Learners in learning Chinese language vocabularies in China?

3. What are the motivations of CFL learners in learning Chinese language vocabularies in China?

\subsection{Research Design}

A study's research design acts as a guideline that offers information on the type of research performed, the type of data to be used and how data will be analyzed (Creswell, 2012). For this study, the descriptive survey design to investigate perceived vocabulary strategies and motivation used by Learners of Chinese as a Foreign Language was used. The quantitative research design was chosen because it enables a researcher to assess attitudes and opinions about individuals, events or procedures (Gay, 1992). In this regard it would enable the researcher to obtain opinions about perceived vocabulary strategies and motivation used by Learners of Chinese as a Foreign Language.

\subsection{Study Population}

The population of the study comprises of all the elements that has features which are useful to the researcher (Mugenda \& Mugenda, 2003). The target population in this research study was Universities in Nanjing. There are 20 Universities in Nanjing with a population of about 2000 postgraduate students.

\subsection{Sampling and Sampling Technique}

Sampling is a process by which a few (samples) from an enlarged group (sampling population) are selected, so that the prevalence, situation or outcome for the larger group, can be estimated or predicted (Egharevba, 2014). Therefore, a sampling technique is a specific method used by a researcher to select respondents for a study. A stratified random sampling technique was used to select the participants in various universities and departments. This involved dividing the population into several groups or strata, where members of a group share a particular characteristic (Robson, 2002). The targeted sample included 120 CFL learners both bachelor and postgraduates from different disciplines from the various universities. This technique was chosen because it guaranteed the desired representation thus increasing the efficiency of the population estimate (Gay, 1992).

\subsection{Data Collection Procedure}

To carry out the study, the researcher developed online questionnaire that was used in the compilation of information. The questionnaire tool was in the form of both open-ended and closed-ended in nature. The significance of the online questionnaire was deemed convenient owing to the prevalent coronavirus pandemic. Saunder et al (2003) recommends that questionnaire is piloted to make sure it is valid and sound. The researcher piloted the questionnaire and improvements were made so that respondents could respond with little difficulty and no problems encountered in recording the information.

\subsection{Questionnaire for CFL Learners}

This questionnaire aimed to find out the perceived vocabulary strategies and motivation used by Learners of Chinese as a Foreign Language. Two separate self-administered semi-structured questionnaires were developed for all selected students. Questionnaires with 5 point Likert scale was used to collect information. First, the researcher made known the objective and the format to be followed while filling up the questionnaire. The first part sought their demographic data. The second section sought their perception of Chinese vocabulary learning difficulties encountered by CFL Learners in China using a 5 point Likert scale with 8 generated items adopted from (Tahsildar, 2019). The third section sought to investigate the strategies adopted by CFL Learners. The study used Schmitt's Vocabulary Learning Strategies Questionnaire (VLSQ) adopted by Bennett (2006). It is a 40item Likert-scale questionnaire with a reliability coefficient of 0.83 for this study. The learners gave their responses on five-point Likert scales, with the available answers being: never (1), seldom (2), sometimes (3), often (4), and always (5). Lastly the researcher determined the motivations for learning Chinese vocabularies using a 5 point Likert scale with 12 generated items adopted from Wen (1997) study.

\subsection{Validity and Reliability}

Validity is defined by Mugenda and Mugenda as the ability of an instrument to accurately measure what it is intended to measure. In order to ensure the validity of the research instrument, the items on the instrument were reviewed by the researcher under the guidance of the supervisor. According to Orodo (2005) the use of a pilot study is one of the ways to ensure that the items on the questionnaire measure what it is intended to measure and also the wordings in the questions are clear and also 
there is the avoidance of questions which are ambiguous. To ensure the validity of this instrument/questionnaire, a pilot study was conducted among twenty (20) respondents and questions that were not properly worded were identified and rectified by the researcher with support from the supervisor before the actual questionnaire was administered to the respondents.

Reliability means measuring the extent to which consistency outcomes or information from repeated trials are produced by study instruments (Mugenda and Mugenda, 2003). That's how consistent the score is for each person from one instrument to another from one item to another. This study gathered the pilot data from individual contacts that would make the researcher familiar with issues in the sector during the main study. Regarding reliability, the research instruments should be consistent in measuring the variables under study (Creswell, 2012). Reliability statistics were conducted using the SPSS software (version 21), and the results are presented in Table 1 below;

\section{Table 1 Reliability Statistics of Variables}

\begin{tabular}{|l|c|c|}
\hline \multicolumn{1}{|c|}{ Variables } & Items & Cronbach Alpha \\
\hline $\begin{array}{l}\text { Chinese vocabulary learning difficulties of } \\
\text { CFL learners }\end{array}$ & 8 & 0.852 \\
\hline $\begin{array}{l}\text { Strategies adopted by CFL learners in } \\
\text { learning vocabulary }\end{array}$ & 30 & 0.934 \\
$\begin{array}{l}\text { Motivations for learning Chinese } \\
\text { vocabularies }\end{array}$ & 12 & 0.875 \\
\hline
\end{tabular}

Items on a questionnaire are statistically reliable if the Cronbach alpha values are higher than 0.7 (Tavakol and Dennick, 2011). The items used to estimate the variables under analysis are statistically reliable from table 3.1 since they are larger than 0.7 .

\subsection{Data Analysis}

The data gathered from questionnaires was analyzed using the Statistical Package for Social Sciences (SPSS) version 22. The researcher made use of descriptive statistics (frequencies and percentages) to describe the responses of the items on the questionnaire as indicated by the respondents.

\subsection{Ethical Issues}

The following ethical issues were considered whilst performing the research which involved;

The researcher kept the information provided by the respondents confidential and respected their privacy. This was achieved by making sure that every questionnaire acquired from the respondents was kept in safety and not made available to any third party for any reason.

The researcher made sure that the questionnaire provided did not include a section that allowed them to provide details that would disclose their identity, to protect the privacy of the respondents.

The respondents were also properly briefed about the purpose of the study. This allowed the respondents to determine whether or not to take part in the study. In no way had the respondents been compelled to participate against their will. Participation was entirely voluntary.

Finally, the researcher respected intellectual property by avoiding any form of plagiarism or passing any work as his own. All statements, knowledge and insights from academic sources were duly referenced with the appropriate referencing guidelines.

\section{Presentation and Discussion of Results}

4.1 Demographic Data of Respondents

In this section, results on the demographic data of the respondents are presented which comprises of their gender, age and level and first language spoken.

\subsubsection{Distribution of the respondents by gender}


The respondents were asked to state their gender and the result of the findings are shown in Table 1 below.

Table 2: Distribution of the respondents by gender

\begin{tabular}{|c|c|c|c|c|}
\hline \multicolumn{2}{|c|}{ Gender } & Frequency & Percent & Cumulative Percent \\
\hline \multirow{3}{*}{ Valid } & Female & 75 & 68.2 & 68.2 \\
\cline { 2 - 5 } & Male & 35 & 31.8 & 100.0 \\
\cline { 2 - 5 } & Total & 110 & 100.0 & \\
\cline { 2 - 5 } & & & & \\
\hline
\end{tabular}

Table 1 shows the distribution of respondents by gender. The results indicate that majority of CFL learners who participated in the study were females represented by $68.2 \%$ and males comprising of $31.8 \%$ of the total participant. This means that majority of CFL learners are females compared to males.

\subsubsection{Distribution of the respondents by Age}

The respondents were asked to state their age and the result of the findings are shown in table 4.2 below.

Table 3: Distribution of respondents by age

\begin{tabular}{|c|c|c|c|}
\hline Respondents & Gender & Frequency & Percentage (\%) \\
\hline \multirow{2}{*}{$\begin{array}{c}\text { CFL Learners } \\
(\mathrm{N}=110)\end{array}$} & $20-25$ years & 49 & 34.5 \\
\cline { 2 - 4 } & $26-30$ years & 38 & 13.6 \\
\cline { 2 - 4 } & $31-35$ years & 15 & 4.5 \\
\cline { 2 - 4 } & $36-40$ years & 5 & 2.7 \\
\hline
\end{tabular}

The findings presented in Table 2 shows that $44.50 \%$ of CFL learners were between $20-25$ years, $34.5 \%$ were of age 26 to 30 years, $13.6 \%$ were of age 31 to 35 years and $4.5 \%$ were of age 36 to 40 years. Only 3 CFL learners were Above 40 years. This means most CFL learners are within the youthful age who want to stay abreast with the Chinese language.

\subsubsection{Distribution of the respondents by Level}

The respondents were asked to state their level and the result of the findings are shown in Table 3 below.

Table 4: Distribution of the respondents by Level

\begin{tabular}{|c|c|c|c|c|}
\hline \multicolumn{2}{|c|}{ Level } & Frequency & Percent & Cumulative Percent \\
\hline \multirow{2}{*}{} & Bachelor & 55 & 50.0 & 50.0 \\
\cline { 2 - 5 } & Masters & 47 & 42.7 & 92.7 \\
\hline
\end{tabular}




\begin{tabular}{|l|c|c|c|c|}
\hline & PhD & 8 & 7.3 & 100 \\
\hline & Total & 110 & 100.0 & \\
\hline
\end{tabular}

From the findings in Table 3, majority of CFL students who participated in the study were at bachelor students represented by $50.0 \%$. CFL students at Masters Level follow with $42.7 \%$ representation and $7.3 \%$ of CFL students at PhD participated in the study.

\subsubsection{Distribution of the respondents by First Language spoken}

The respondents were asked to indicate their first language spoken and the result of the findings are shown in table 4 below.

Table 5 Distribution of the respondents by First Language spoken

\begin{tabular}{|c|c|c|c|}
\hline Level & Frequency & Percent & Cumulative Percent \\
\hline English & 32 & 29.1 & 29.1 \\
\hline French & 17 & 15.5 & 44.6 \\
\hline Persian & 8 & 7.2 & 51.8 \\
\hline Arabic & 7 & 6.3 & 58.1 \\
\hline Afrikaans & 10 & 9.1 & 67.2 \\
\hline Swahili & 7 & 6.3 & 73.5 \\
\hline Spanish & 23 & 20.9 & 94.4 \\
\hline Urdu & 4 & 3.6 & 98 \\
\hline Others & 2 & 1.8 & 100 \\
\hline Total & 110 & 100.0 & \\
\hline
\end{tabular}

From the findings in Table 4, English (29.1\%) was identified as the first language spoken by most CFL students. This was followed by CFL learners who speak Spanish (20.9) as their first language. CFL learners who speak French as their first language followed closely at $15.5 \%$ representatives. Two participants represented speakers of other language were represented by 2 participants who indicated they speak Bengali and Portuguese respectively.

\subsection{Objective 1: Perceived learning difficulties encountered by CFL Learners in China}

In this section the respondents were asked to evaluate their perceived Chinese vocabulary learning difficulties on a 1-5 Likert scale. The findings are presented in table 5 below;

Table 6 Perceived Chinese vocabulary learning difficulties

\begin{tabular}{|l|c|c|c|}
\hline $\begin{array}{l}\text { Perceived Chinese vocabulary learning } \\
\text { difficulties }\end{array}$ & N & Mean & $\begin{array}{l}\text { Standard } \\
\text { Deviation }\end{array}$ \\
\hline $\begin{array}{l}\text { 1. Choosing proper words in Chinese vocabulary } \\
\text { learning is the most difficult }\end{array}$ & 110 & 3.48 & 1.16 \\
\hline $\begin{array}{l}\text { 2. The most difficult part in learning Chinese is } \\
\text { learning the Characters. }\end{array}$ & & 110 & 4.33 \\
\hline
\end{tabular}




\begin{tabular}{|c|c|c|c|}
\hline $\begin{array}{l}\text { 3. Differentiating the tones in words are the most } \\
\text { difficult in learning oral Chinese vocabulary. }\end{array}$ & 110 & 3.12 & .86 \\
\hline $\begin{array}{l}\text { 4. Sound similarities in oral communication are } \\
\text { most challenging in learning Chinese. }\end{array}$ & 110 & 4.48 & 1.05 \\
\hline $\begin{array}{l}\text { 5. Finding the proper words in expressing } \\
\text { meaning in oral Chinese is the most complicated. }\end{array}$ & 110 & 3.95 & 1.03 \\
\hline $\begin{array}{l}\text { 6. Chinese Grammar is the most difficult part of } \\
\text { learning Chinese. }\end{array}$ & 110 & 4.01 & .90 \\
\hline $\begin{array}{l}\text { 7. I always have difficulties remembering Chinese } \\
\text { words that I try to memorize. }\end{array}$ & 110 & 4.07 & .72 \\
\hline $\begin{array}{l}\text { 8. I always have difficulties in using words in the } \\
\text { right context in oral Chinese. }\end{array}$ & 110 & 3.85 & 1.10 \\
\hline
\end{tabular}

As shown in Table 5, the statistics demonstrates that for perceived Chinese vocabulary learning difficulties; the item in which the participants showed the highest level of agreement is sound similarities in oral communication are most challenging in learning Chinese with a mean score of 4.48 . This was followed by participants who agreed to "The most difficult part in learning Chinese is learning the Characters" as the $2^{\text {nd }}$ highest ranked perceived difficulty with a mean value of 4.33 . "I always have difficulties remembering Chinese words that I try to memorize" was agreed by respondents as the third ranked difficulty in learning Chinese vocabulary with a mean value of 4.07. Following this, "Chinese Grammar is the most difficult part of learning Chinese" is indicated as the fourth most difficulty part of learning Chinese vocabulary with a mean value of 4.01 . For the rest of items, 5,8 and 1 were ranked as the $5^{\text {th }}, 6^{\text {th }}$ and $7^{\text {th }}$ respectively; the participants also represent a higher level of agreement. Among the 8 items, item 3, "Differentiating the tones in words are the most difficult in learning oral Chinese vocabulary", is believed to be the least vocabulary learning difficulty by the respondents $(M=.3 .12)$. Hence, it could be assumed that the participants agree with the total items in perceived Chinese vocabulary learning difficulties.

The research findings are congruent with research findings of literature in some aspects. For instance, Tahsildar (2019) study investigated Chinese linguistic complexities among international students enrolled in Chinese courses in China and he found sound similarities as a major challenge. This was no different to research findings of Wang, Perfetti, \& Liu (2005) that also discovered in a study conducted at an American college that students who study Chinese for one semester face significant challenges in learning the tones, which are primarily due to a lack of tonal characteristics in the students' native languages. They go on to say that another challenge for Chinese foreign language learners is a large number of homophones in the Chinese language.

\subsubsection{Objective 2: Strategies adopted by CFL Learners in learning Chinese language vocabularies}

In this section the respondents were asked to rate the strategies adopted in learning Chinese language vocabularies on a 1-5 Likert scale. The findings are presented in Table 6 below;

Table 7 Strategies adopted by CFL Learners in learning Chinese language vocabularies

\begin{tabular}{|l|l|l|c|c|}
\hline \multicolumn{2}{|c|}{ Item number and strategy } & Category & Mean & $\begin{array}{l}\text { Standard } \\
\text { Deviation }\end{array}$ \\
\hline When I find a new Chinese word that I don't know, I... & & & 3.56 & 0.95 \\
\hline 1 & Check the new word's form (verb, noun etc. & COG & 3.36 & 1.07 \\
\hline 2 & Use any pictures or gestures to help me guess & MEM & 4.75 & 1.05 \\
\hline 3 & Use a Chinese-English dictionary & COG & 3.58 & 0.99 \\
\hline
\end{tabular}




\begin{tabular}{|c|c|c|c|c|}
\hline 5 & Ask your classmates for the meaning & SOC & 4.03 & 0.79 \\
\hline 6 & Study the word with your classmates & SOC & 3.39 & 1.12 \\
\hline 7 & Talk with native speakers & SOC & 4.00 & 0.91 \\
\hline 8 & Draw a picture of the word to help remember it & MEM & 3.65 & 1.05 \\
\hline 9 & Make a mental image of the word's meaning & MEM & 3.34 & 0.99 \\
\hline 10 & Connect the word to a personal experience & MEM & 3.45 & 1.07 \\
\hline 11 & Remember the words that follow or precede the new word & MEM & 4.24 & 0.85 \\
\hline 12 & $\begin{array}{l}\text { Connect the word to other words with similar or opposite } \\
\text { meanings }\end{array}$ & MEM & 3.10 & 0.92 \\
\hline 13 & Group words together to study them & MEM & 3.65 & 1.08 \\
\hline 14 & Use new words in sentences & COG & 3.20 & .89 \\
\hline 15 & Write paragraphs using several new words & MET & 3.31 & .89 \\
\hline 16 & Study the spelling of a word & MEM & 4.55 & 0.76 \\
\hline 17 & Study the sound of a word & MEM & 3.15 & 0.83 \\
\hline 18 & Say the new words aloud when you first meet them & COG & 3.37 & 1.06 \\
\hline 19 & Make a mental image of the word's form & MEM & 4.42 & 0.77 \\
\hline 20 & $\begin{array}{l}\text { Remember the word using its parts (im-, un-, -able, -ful, -ment, } \\
\text { ex- }\end{array}$ & MEM & 3.99 & 1.33 \\
\hline 21 & Make your own definition for the word & COG & 2.90 & 1.03 \\
\hline 22 & Use physical action when learning a word & COG & 2.74 & 1.24 \\
\hline 23 & Repeat the words aloud many times & COG & 3.35 & 0.95 \\
\hline 24 & Write the words many times & MEM & 2.93 & 1.36 \\
\hline 25 & Make lists of new words & MET & 3.31 & 1.14 \\
\hline 26 & Use flash cards to record new words & COG & 4.04 & 0.87 \\
\hline 27 & Take notes or highlight new words in class & MET & 4.45 & 0.76 \\
\hline 28 & Practice the words by watching Chinese movies and TV & COG & 3.34 & 1.23 \\
\hline 29 & Test yourself with word tests & MET & 3.78 & 1.22 \\
\hline 30 & Ask others to correct one's pronunciation when speaking & SOC & 2.52 & 1.16 \\
\hline
\end{tabular}

The descriptive statistics showed that the means of the 30 strategy items ranged from 2.52 to 4.75 . The 30 strategy items from the CVLSQ were classified into three groups based on their frequency of use. Group 1 comprised the most-commonly-used strategies. Each strategy in Group 1 had a mean equal to or above 3.5. The strategies in Group 2 were less-commonly used with each strategy either having a mean between 3.0 and 3.5. The strategies in Group 3 were least-commonly used with each strategy having a mean equal to or less than 3.0. Of the 30 strategies listed, 14 were classified as the most-commonly-used strategies. 
The Mean and standard deviation of participants choosing either 4 or 5 for the 20 most-commonly-used strategy items are provided in Table 7.

Table 8 Strategies Most-Commonly Used by CFL learners in Learning Chinese Vocabularies

\begin{tabular}{|c|c|c|c|c|}
\hline \multicolumn{2}{|r|}{ Item number and strategy } & \multirow{2}{*}{$\begin{array}{l}\text { Category } \\
\text { COG }\end{array}$} & \multirow{2}{*}{$\begin{array}{l}\text { Mean } \\
3.56\end{array}$} & \multirow{2}{*}{$\begin{array}{r}\begin{array}{l}\text { Standard } \\
\text { Deviation }\end{array} \\
0.95\end{array}$} \\
\hline 1 & Check the new word's form (verb, noun etc. & & & \\
\hline 3 & Use a Chinese-English dictionary & COG & 4.75 & 1.05 \\
\hline 4 & Ask the teacher to give you the definition or a sentence & SOC & 3.58 & 0.99 \\
\hline 5 & Ask your classmates for the meaning & SOC & 4.03 & 0.79 \\
\hline 7 & Talk with native speakers & SOC & 4.00 & 0.91 \\
\hline 8 & Draw a picture of the word to help remember it & MEM & 3.65 & 1.05 \\
\hline 11 & Remember the words that follow or precede the new word & MEM & 4.24 & 0.85 \\
\hline 13 & Group words together to study them & MEM & 3.65 & 1.08 \\
\hline 16 & Study the spelling of a word & MEM & 4.55 & 0.76 \\
\hline 19 & Make a mental image of the word's form & MEM & 4.42 & 0.77 \\
\hline 20 & $\begin{array}{l}\text { Remember the word using its parts (im-, un-, -able, -ful, -ment, } \\
\text { ex- }\end{array}$ & MEM & 3.99 & 1.33 \\
\hline 26 & Use flash cards to record new words & COG & 4.04 & 0.87 \\
\hline 27 & Take notes or highlight new words in class & MET & 4.45 & 0.76 \\
\hline 29 & Test yourself with word tests & MET & 3.78 & 1.22 \\
\hline
\end{tabular}

As shown in Table 7, of the 14 most-commonly used strategies, 3 were cognitive strategies (1, 3, and 26). The 14 mostcommonly used strategies also included two metacognitive strategies $(27,29)$, which focus on the planning and monitoring of one's vocabulary learning such as previewing the new words before class and noticing the incorrect word usage and using that information to improve. Three social strategies $(4,5$, and 7$)$ were also in the top 14 strategies. Six memory strategies $(8,11,13$, 16,19 , and 20) were most commonly used by the CFL learners, that is, paying attention to known characters when memorizing a word and quizzing oneself during memorization of characters (words).

The 12 strategies listed in Table 8 were less-commonly used by the students. Each strategy item in this group either had a mean between 3.0 and 3.5. The means of these strategy items ranged from 3.10 to 3.45 (Table 8).

Table 9 Strategies Less-Commonly Used by CFL learners in Learning Chinese Vocabularies

\begin{tabular}{|l|l|l|c|c|}
\hline \multicolumn{2}{|c|}{ Item number and strategy } & Category & Mean & $\begin{array}{l}\text { Standard } \\
\text { Deviation }\end{array}$ \\
\hline 2 & Use any pictures or gestures to help me guess & MEM & 3.36 & 1.07 \\
\hline 6 & Study the word with your classmates & SOC & 3.39 & 1.12 \\
\hline 9 & Make a mental image of the word's meaning & MEM & 3.34 & 0.99 \\
\hline
\end{tabular}




\begin{tabular}{|c|c|c|c|c|}
\hline 10 & Connect the word to a personal experience & MEM & 3.45 & 1.07 \\
\hline 12 & $\begin{array}{l}\text { Connect the word to other words with similar or opposite } \\
\text { meanings }\end{array}$ & MEM & 3.10 & 0.92 \\
\hline 14 & Use new words in sentences & COG & 3.20 & .89 \\
\hline 15 & Write paragraphs using several new words & MET & 3.31 & .89 \\
\hline 17 & Study the sound of a word & MEM & 3.15 & 0.83 \\
\hline 18 & Say the new words aloud when you first meet them & COG & 3.37 & 1.06 \\
\hline 23 & Repeat the words aloud many times & COG & 3.35 & 0.95 \\
\hline 25 & Make lists of new words & MET & 3.31 & 1.14 \\
\hline 28 & Practice the words by watching Chinese movies and TV & COG & 3.34 & 1.23 \\
\hline
\end{tabular}

Of the 12 less-commonly-used strategies, 5 were memory strategies $(2,9,10,12,17)$, 4 were cognitive strategies $(14,18,23,28)$, 2 metacognitive strategies $(15,25)$, and only one was social strategy (6).

The least-commonly-used strategies are listed in Table 9. Each of the least commonly-used strategy items had a mean less than 3.0. The means of these strategy items ranged from 2.52 to 2.93 .

Table 10 Strategies Least-Commonly Used by CFL learners in Learning Chinese Vocabularies

\begin{tabular}{|l|l|l|c|c|}
\hline \multicolumn{2}{|c|}{ Item number and strategy } & Category & Mean & $\begin{array}{l}\text { Standard } \\
\text { Deviation }\end{array}$ \\
\hline 21 & Make your own definition for the word & COG & 2.90 & 1.03 \\
\hline 22 & Use physical action when learning a word & COG & 2.74 & 1.24 \\
\hline 24 & Write the words many times & MEM & 2.93 & 1.36 \\
\hline 30 & Ask others to correct one's pronunciation when speaking & SOC & 2.52 & 1.16 \\
\hline
\end{tabular}

Among the four strategies, two were cognitive strategies $(21,22)$, one was memory strategy $(24)$ and one was social strategy (30). Even though writing Chinese characters by hand is commonly believed to help students better retain the vocabulary words learned, writing the words many times were least-commonly used.

The tables above listed the individual strategies that were most-commonly, less-commonly, and least-commonly used by the participants. The strategy use by categories (cognitive, memory, metacognitive, and social) is summarized in Table 10, which shows that $50 \%$ of the metacognitive strategies, $48 \%$ of the cognitive strategies, and $40 \%$ of the social strategies were mostcommonly used, whereas only $17 \%$ of the memory strategies were most-commonly used.

Table 11 Percentage Representation of Four Types of Strategies by Groups

\begin{tabular}{|l|c|c|c|c|}
\hline Groups & $\begin{array}{c}\text { SOCIA } \\
\mathrm{L}\end{array}$ & $\begin{array}{c}\text { MEMOR } \\
\mathrm{Y}\end{array}$ & $\begin{array}{c}\text { COGNITIV } \\
\mathrm{E}\end{array}$ & METACOGNITIVE \\
\hline $\begin{array}{l}\text { Most commonly- } \\
\text { used strategies }\end{array}$ & $21.4 \%$ & $42.9 \%$ & $21.4 \%$ & $14.3 \%$ \\
\hline less-commonly-used & $8.3 \%$ & $41.7 \%$ & $33.3 \%$ & $16.7 \%$ \\
strategies & & & & \\
\hline
\end{tabular}




\begin{tabular}{|l|l|l|l|l|}
\hline $\begin{array}{l}\text { least-commonly-used } \\
\text { strategies }\end{array}$ & $25 \%$ & $25 \%$ & $50 \%$ & $0 \%$ \\
\hline
\end{tabular}

\subsubsection{Objective 3: CFL learners' motivations for learning Chinese language vocabularies in China}

In this section the respondents were asked to indicate their level of agreement to the motivations for learning Chinese language vocabularies in China on a 1-5 Likert scale. The findings are presented in Table 11 below;

Table 12 CFL learners' motivations for learning Chinese language vocabularies

\begin{tabular}{|c|c|c|c|c|}
\hline \multicolumn{2}{|c|}{ Item number and motivational item } & $\mathbf{N}$ & Mean & $\begin{array}{l}\text { Standard } \\
\text { Deviation }\end{array}$ \\
\hline 1 & $\begin{array}{l}\text { so that I will be able to better understand } \\
\text { and appreciate Chinese art and literature. }\end{array}$ & 110 & 3.58 & 1.07 \\
\hline 2 & $\begin{array}{l}\text { so that } 1 \text { will be able to meet and converse } \\
\text { with more and varied people. }\end{array}$ & 110 & 4.02 & 0.98 \\
\hline 3 & $\begin{array}{l}\text { because I want to learn about other cultures } \\
\text { to understand the world better. }\end{array}$ & 110 & 4.24 & 0.86 \\
\hline 4 & $\begin{array}{l}\text { because of interest in my own Oriental } \\
\text { heritage. }\end{array}$ & 110 & 3.76 & 1.04 \\
\hline 5 & $\begin{array}{l}\text { because I feel Chinese is an important } \\
\text { language in the economic development of } \\
\text { the world. }\end{array}$ & 110 & 3.43 & 1.24 \\
\hline 6 & $\begin{array}{l}\text { because it will help me to better understand } \\
\text { the problems that Chinese speakers face. }\end{array}$ & 110 & 3.36 & 1.54 \\
\hline 7 & $\begin{array}{l}\text { because I think it will someday be useful in } \\
\text { getting a good job. }\end{array}$ & 110 & 4.45 & 0.67 \\
\hline 8 & $\begin{array}{l}\text { because I want to be able to use it with } \\
\text { Chinese-speaking friends }\end{array}$ & 110 & 4.05 & 0.86 \\
\hline 9 & $\begin{array}{l}\text { because I want to use Chinese when I travel } \\
\text { to a Chinese speaking country }\end{array}$ & 110 & 4.12 & 0.95 \\
\hline 10 & $\begin{array}{l}\text { because I need to study a foreign language } \\
\text { as a requirement for my degree }\end{array}$ & 110 & 4.54 & 0.63 \\
\hline 11 & $\begin{array}{l}\text { because I feel the class is less demanding } \\
\text { than other five-unit courses }\end{array}$ & 110 & 2.76 & 1.78 \\
\hline 12 & because I need it for study abroad. & 110 & 3.87 & 1.88 \\
\hline
\end{tabular}

The descriptive statistics showed that the means of the 12 motivational items ranged from 2.76 to 4.54 . From the findings in Table 11, most CFL learners are motivated by "because I need to study a foreign language as a requirement for my degree $(M=4.54)$. The CFL learners were motivated strongly by "because I think it will someday be useful in getting a good job" ranking second $(M=4.45)$. The $3^{\text {rd }}$ ranked motivation "because I want to learn about other cultures to understand the world better" was agreed by CFL learners with a mean value of 4.24. Respondents also agreed to "because I want to use Chinese when I travel to a Chinese speaking country" ranking as the fourth motivational item $(M=4.12)$. Respondents also agreed to "because I want to be able to use it with Chinese-speaking friends" ranking as the fifth motivational item $(M=4.05)$. Item 2, "so that 1 will be able to meet and converse with more and varied people" came as the $6^{\text {th }}$ ranked top ranked motivational item. 
The lowest ranked motivational items were as follows: 12, 4, 1, 5 and 6 . However, the respondents disagreed to "because I feel the class is less demanding than other five-unit courses" with a mean value of 2.76 .

Comparing with literature, the researcher identified similarity with Mandell (2002) and Wen's (1997) study findings. Mandell (2002) study finding asserted majority of beginning Spanish learners were enrolled in language classes to meet the institution's requirement, based on his study of university-level Spanish learners. Similarly, Wen's (1997) asserted the motivating factors of students from Asian and Asian-American backgrounds studying Chinese at American universities showed that interest in Chinese culture, as well as a desire to understand one's heritage and culture, motivated students to learn Chinese.

\section{Summary of findings, conclusions and recommendations}

\subsection{Summary of findings}

The study focused on examining perceived Vocabulary strategies and Motivation used by Learners of Chinese as a Foreign Language. The first objective of the study sought to identify perceived learning difficulties encountered by CFL Learners in China. According to the results, the following perceived learning difficulties were discovered in their order of difficulty: Sound similarities in oral communication, learning the Characters, Remembering Chinese words that I try to memorize, Chinese Grammar, Finding the proper words in expressing meaning in oral Chinese, using words in the right context in oral Chinese, choosing proper words in Chinese vocabulary learning and differentiating the tones in words.

The second objective of the study sought to evaluate strategies adopted by CFL Learners in learning Chinese language vocabularies. Their responses were grouped into most commonly used, less-commonly used and least-commonly used. Likewise, the items were categorized into social, memory, cognitive and metacognitive strategies. The findings revealed that most commonly-used strategies by CFL learners were memory strategies. However, the most commonly-used strategy with highest mean value was a cognitive strategy which revealed CFL learners use a Chinese-English dictionary to learn Chinese Vocabularies. The less-commonly used strategies were memory strategies. The less-commonly used strategy with the highest mean value is a memory strategy which revealed CFL learners "Connect the word to a personal experience" to learn Chinese Vocabularies. Cognitive strategies were identified to be the least-commonly used strategies with the highest frequency. The least-commonly used strategy with the highest mean value is a memory strategy which revealed CFL learners "Write the words many times" whiles the least-commonly used strategy with the lowest mean value is a social strategy which revealed CFL learners "Ask others to correct one's pronunciation when speaking".

The third objective of the study sought to find out CFL learners' motivations for learning Chinese language vocabularies in China. From the findings CFL learners were motivated by these factors in their order of importance: "because I need to study a foreign language as a requirement for my degree, "because I think it will someday be useful in getting a good job", "because I want to learn about other cultures to understand the world better", "because I want to use Chinese when I travel to a Chinese speaking country", "because I want to be able to use it with Chinese-speaking friends", "so that I will be able to meet and converse with more and varied people". The lowest ranked motivational items were as follows: "because I need it for study abroad", "because of interest in my own Oriental heritage", "so that I will be able to better understands and appreciates Chinese art and literature", "because I feel Chinese is an important language in the economic development of the world" and "because it will help me to better understand the problems that Chinese speakers face".

\subsection{Conclusion}

This study focused on examining perceived Vocabulary strategies and Motivation used by Learners of Chinese as a Foreign Language. Theoretically, the present study's findings considerably enrich our knowledge about Chinese vocabulary acquisition particularly with respect to the combined role of strategies and Motivations. Having identified clear cut difficulties experienced by CFL learners in Chinese vocabulary learning memory strategies are the most effective strategies to overcome these difficulties. Most CFL learners' resort to Chinese-English dictionary in learning Chinese vocabulary. However, in using this strategy it won't be enough if CFL learners don't employ memory strategies. This suggests that both cognitive and memory approaches to vocabulary learning can be useful. The results of this study suggest that when students are motivated it plays an important role in starting and continuing in Chinese. Based on the findings most CFL learners are extrinsically than intrinsically driven. They only learn Chinese vocabulary to attain their ultimate goal of obtaining their degree and landing a decent job in the future.

\subsection{Recommendations}

Dwelling on the findings of the study and the conclusions derived from it, the researcher provides the following as recommendations:

1. It is vital for Chinese language instructors to actively encourage students to see vocabulary learning as a rewarding experience, in order to boost their intrinsic motivation to sustained language learning. 
2. Since Chinese language learners in China come from a diverse range of linguistic and ethnic backgrounds, it's crucial to look into the different motivations and aspirations they bring to the Chinese vocabulary learning task, as well as the strategies they use to learn.

3. Since the research reveals that, most foreign students learn Chinese vocabularies under the driven of extrinsic motivation, Chinese language instructors should attach numerous motivational factors in learning Chinese language to boost and sustain learning.

\subsection{Research Limitations and suggestion for further studies}

It is of no doubt that the study has some limitations. Firstly, the sample size. Even though there are a lot of people across the globe who intend to learn Chinese vocabularies, only 120 foreign students participated. Hence, limiting the current study in terms of adequate respondents. Also, respondents of the current study is mainly limited to International students from various Universities in Nanjing-China. Again, due to the limitation of the scope of the current study, the statistical results obtained from the questionnaire might not be generalized to the entire CFL learners.

To sum up, in the future, more research studies on perceived vocabulary strategies and motivation used by CFL learners should be conducted by other researchers. Also, Chinese language and instructors should create a favorable learning environment that will push CFL leaners in china to deploy appropriate strategies to learn vocabularies with ease and become better uses of the language in general.

Funding: The authors of this work solely funded it.

Conflict of Interests: The authors declare no conflict of interest.

\section{References}

[1]. Birdsong, D. (1999). Second Language Acquisition and the Critical Period Hypothesis. New Jersey/London: Lawrence Erlbaum Associates.

[2]. Boonkengsaen, N. (2012). Factors Affecting Vocabulary Learning Strategies; a synthesized study. Noresuan University Journal, 20 (2). 45-53.

[3]. Chamot, A. U. (2001). The role of Learning Strategies in Second Language Acquisition. In M. P. Breen (Ed.), Learner contributions to language learning (24-44).Essex: Pearson Education

[4]. Chiang, M. (2002). An Investigation of Students' Perspective on Chinese language learning. Journal of Chinese Teachers Association, 37(1)4762.

[5]. Coady, J. (1997). L2 Vocabulary Acquisition: A Synthesis of Research. In J. Coady Th.Huckin (Eds.), Second Language Vocabulary Acquisition: a Rationale for Pedagogy (273-91). Cambridge: Cambridge University Press.

[6]. Chang J. (2008). "A research on Chinese as foreign language learners' beliefs of language learning", MA thesis, East China Normal University, Shanghai, China.

[7]. Cohen, A., D. \& Macaro, E. (Eds) (2007) Language Learner Strategies: Thirty years of Research and Practice. Oxford: Oxford University Press.

[8]. Farajee, M., \& Arabmofrad, A. (2015). The Effect of Collaborative Strategic Vocabulary Learning on EFL Learners' Self-efficacy. Journal of Applied Linguistics and Language Research. 2, 103-118.

[9]. Farvardin, M. T., \& Koosha, M. (2011). The Role of Vocabulary Knowledge in EFL Students' Reading Comprehension Performance: Breadth or Depth? Theory and Practice in Language Studies, 1, 1575-1580. doi:10.4304/tpls.1.11.1575 1580

[10]. Gass, S. (1988) Second Language Vocabulary Acquisition. Annual Review of Applied Linguisticsm, 9, 92-106.

[11]. Goh, Christine C.M. \& R.E. Silver. (2004). Language Acquisition and Development. Singapore: Longman.

[12].Halliday, M. A. K. (2014a). Notes on teaching Chinese to foreign learners. Journal of World Languages, 1(1), 1-6.

[13]. Hu, B. (2005). Chinese Tone Learning Strategies and Tone Competence: an Exploratory Study. (Unpublished MSc Dissertation). University of Oxford

[14]. Hui, A.N. (2011). Language Learning Strategy of Hong Kong Putonghua Learners. Educational Research Journal, 26(1),17-39.

[15]. Jiang, X. (2000). Exploration of Learning Strategies in Chinese as a Second Language. Language Teaching and Research. 1, 61-68

[16]. Jiang Y. (2005). A research on English major students' beliefs and strategies of vocabulary learning", MA thesis, Nanjing Normal University, Nanjing, China.

[17]. Macaro, E. (2006). Strategies for Language Learning and for Language Use: Revising the Theoretical Framework. The Modern Language Journal, 90(3), 320-337

[18]. Macaro, E. (2007) Language Learner Strategies. Oxford: Oxford University Press.

[19]. Nation, P. (2001). Learning vocabulary in another language. Cambridge: Cambridge University Press.

[20]. Nirattisal, S. (2014). Vocabulary Learning Strategies of Thai University Students its Relationship to Vocabulary size. International journal of English Language Education, 2(1), 273-287.

[21]. O'Maley, A.U. Chamot. (1990). Learning Strategies in Second Language Acquisition. New York: Cambridge University Press.

[22]. Oxford, R. L., and Scarcellat. (1994). Second Language Vocabulary Learning Among Adults: State of the Art in Vocabulary Instruction. Elsevier Science Ltd, 22(2), 231-243.

[23]. Schmitt, N 2000. Vocabulary in language teaching. Cambridge: Cambridge University Press.Students'. Language Learning, 46(1),101-35 
[24]. Sung, K.-Y., (2011). Factors influencing Chinese language learners' strategy use. International Journal of Multilingualism, 8(2), 117-134.

[25]. Tahsildar, Mohammad Nasim. (2019), Chinese Language Complexities among International Students in China.

[26]. Višnja, P. (2008). Vocabulary Learning Strategies and Foreign Language Acquisition. Great Britain: Cromwell Press Ltd.

[27]. Wenden, A. and Rubin,J. (Eds.). (1987). Learner Strategies in Language Learning. New York: Prentice Hall.

[28]. Wong, L.L.C. \& Nunan, D. (2011). The learning styles and strategies of effective language learners. System, 39,144-163.

[29]. Yan S. H. (2004). A research on Chinese as foreign language learners' vocabulary learning strategies", MA thesis, Beijing Language and Culture University, Beijing, China.

[30]. Yu, B. (2010). Learning Chinese abroad: the role of language attitudes and motivation in the adaptation of international students in China. Journal of Multilingual and Multicultural Development, 31(3), 301-321.

\section{Appendix}

\section{QUESTIONNAIRE FOR CFL LEARNERS}

A dear friend, this questionnaire is designed to help the researcher understand the perceived Vocabulary strategies and Motivation used by Learners of Chinese as a Foreign Language. You are kindly requested to complete all the items in this questionnaire by either ticking $V$ or filling in the appropriate answer in the spaces provided. The results of the study will only be used for informational purposes.

\section{Section A: Demographic Information.}

1. Name:

2. Gender: Male () Female ()

3. Age: Below 18 years ( ) $18-20$ years ( ) $21-23$ years ( ) $24-26$ years ( )

3. Level: Bachelor () Masters () PhD()

4. First Language spoken: English ( ) French ( ) Persian ( ) Arabic ( ) Afrikaans ( ) Swahili ( ) Spanish ( ) Urdu ( ) others (Please specify):

\section{Section B: Perceived vocabulary learning difficulties encountered by CFL Learners in China}

Please evaluate the expressions given using the 1-5 Likert scale on the Perceived vocabulary learning difficulties encountered in learning Chinese language. Indicate your level of agreement using the scoring criteria below:

1- Strongly Disagree 2- Disagree 3- Neutral 4- Agree 5- Strongly Agree

\begin{tabular}{|c|c|c|c|c|c|}
\hline $\begin{array}{l}\text { Perceived } \\
\text { vocabulary learning } \\
\text { difficulties }\end{array}$ & $\begin{array}{l}\text { Strongly } \\
\text { Disagree }\end{array}$ & Disagree & Neutral & Agree & $\begin{array}{c}\text { Strongly } \\
\text { Agree }\end{array}$ \\
\hline $\begin{array}{l}\text { 1. Choosing proper } \\
\text { words in oral Chinese } \\
\text { learning is the most } \\
\text { difficult }\end{array}$ & & & & & \\
\hline $\begin{array}{l}\text { 2. The most difficult } \\
\text { part in learning } \\
\text { Chinese vocabulary is } \\
\text { learning the } \\
\text { Characters. }\end{array}$ & & & & & \\
\hline $\begin{array}{l}\text { 3. Differentiating the } \\
\text { tones in words are } \\
\text { the most difficult in } \\
\text { learning oral Chinese } \\
\text { words. }\end{array}$ & & & & & \\
\hline $\begin{array}{l}\text { 4. Sound similarities } \\
\text { in oral } \\
\text { communication are } \\
\text { most challenging in } \\
\text { learning Chinese } \\
\text { words. }\end{array}$ & & & & & \\
\hline $\begin{array}{l}\text { 5. Finding the proper } \\
\text { words in expressing } \\
\text { meaning in oral } \\
\text { Chinese is the most } \\
\text { complicated. }\end{array}$ & & & & & \\
\hline $\begin{array}{l}\text { 6. Chinese Grammar } \\
\text { is the most difficult } \\
\text { part of learning } \\
\text { Chinese words. }\end{array}$ & & & & & \\
\hline
\end{tabular}




\begin{tabular}{|l|l|l|l|l|l|}
\hline $\begin{array}{l}\text { 7. I always have } \\
\text { difficulties } \\
\text { remembering } \\
\text { Chinese words that I } \\
\text { try to memorize. }\end{array}$ & & & & & \\
\hline $\begin{array}{l}8 . \text { I always have } \\
\text { difficulties in using } \\
\text { words in the right } \\
\text { context in oral }\end{array}$ & & & & & \\
Chinese. & & & & & \\
\hline
\end{tabular}

\section{Section C: Strategies adopted by CFL Learners in learning Chinese language vocabularies}

Please evaluate the expressions given using the 1-5 Likert scale on the strategies adopted in learning Chinese language vocabularies. Indicate the frequency using the scoring criteria below:

Scoring criteria: 1 - never, 2- seldom, 3- sometimes, 4- often and 5- very often

\begin{tabular}{|c|c|c|c|c|c|}
\hline & Never & Seldom & sometimes & often & $\begin{array}{l}\text { very } \\
\text { often }\end{array}$ \\
\hline \multicolumn{6}{|l|}{$\begin{array}{l}\text { When I find a new Chinese word that I don't know, } \\
\text { I... }\end{array}$} \\
\hline $\begin{array}{l}\text { Check the new word's form (verb, noun } \\
\text { etc. }\end{array}$ & & & & & \\
\hline $\begin{array}{l}\text { Use any pictures or gestures to help me } \\
\text { guess }\end{array}$ & & & & & \\
\hline Use a Chinese-English dictionary & & & & & \\
\hline $\begin{array}{l}\text { Ask the teacher to give you the definition } \\
\text { or a sentence }\end{array}$ & & & & & \\
\hline Ask your classmates for the meaning & & & & & \\
\hline Study the word with your classmates & & & & & \\
\hline Talk with native speakers & & & & & \\
\hline $\begin{array}{l}\text { Draw a picture of the word to help } \\
\text { remember it }\end{array}$ & & & & & \\
\hline $\begin{array}{l}\text { Make a mental image of the word's } \\
\text { meaning }\end{array}$ & & & & & \\
\hline $\begin{array}{l}\text { Connect the word to a personal } \\
\text { experience }\end{array}$ & & & & & \\
\hline $\begin{array}{l}\text { Remember the words that follow or } \\
\text { precede the new word }\end{array}$ & & & & & \\
\hline $\begin{array}{l}\text { Connect the word to other words with } \\
\text { similar or opposite meanings }\end{array}$ & & & & & \\
\hline Group words together to study them & & & & & \\
\hline Use new words in sentences & & & & & \\
\hline $\begin{array}{l}\text { Write paragraphs using several new } \\
\text { words }\end{array}$ & & & & & \\
\hline Study the spelling of a word & & & & & \\
\hline Study the sound of a word & & & & & \\
\hline $\begin{array}{l}\text { Say the new words aloud when you first } \\
\text { meet them }\end{array}$ & & & & & \\
\hline Make a mental image of the word's form & & & & & \\
\hline $\begin{array}{l}\text { Remember the word using its parts (im-, } \\
\text { un-, -able, -ful, -ment, ex- }\end{array}$ & & & & & \\
\hline Make your own definition for the word & & & & & \\
\hline Use physical action when learning a word & & & & & \\
\hline Repeat the words aloud many times & & & & & \\
\hline Write the words many times & & & & & \\
\hline Make lists of new words & & & & & \\
\hline
\end{tabular}




\begin{tabular}{|l|l|l|l|l|l|l|}
\hline & Use flash cards to record new words & & & & & \\
\hline & $\begin{array}{l}\text { Take notes or highlight new words in } \\
\text { class }\end{array}$ & & & & & \\
\hline Keep a vocabulary notebook & & & & & \\
\hline & Test yourself with word tests & & & & & \\
\hline & Study new words many times & & & & & \\
\hline
\end{tabular}

Section D: CFL learners' motivations for learning Chinese language vocabularies in China.

Please evaluate the expressions given using the 1-5 Likert scale on motivations for learning Chinese language vocabularies. Indicate your level of agreement using the scoring criteria below:

1- Strongly Disagree 2- Disagree 3- Neutral 4- Agree 5- Strongly Agree

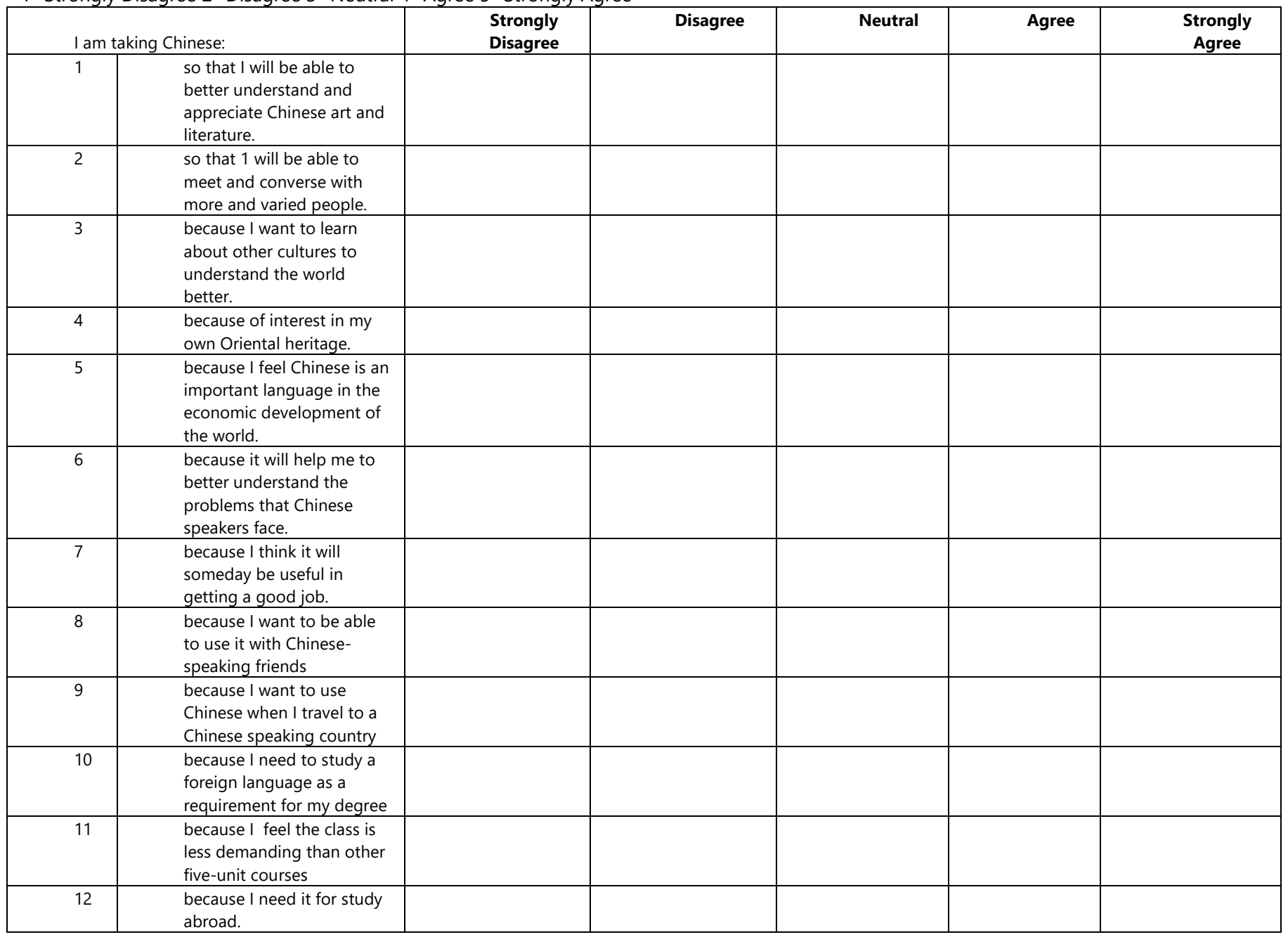

Thank you!! 